\title{
0 rápido processo de envelhecimento populacional do Brasil: sérios desafios para as políticas públicas*
}

\author{
Laura L. Rodríguez Wong ${ }^{\star \star}$ \\ J. A. Carvalho***
}

\begin{abstract}
Já são sentidos, no Brasil, os efeitos positivos da transição na estrutura etária (TEE), por exemplo, nos serviços de saúde à infância e na educação. $O$ crescimento diferenciado previsto para a população em idade ativa (PIA), nas próximas décadas, constitui uma nova janela de oportunidades. Com efeito, a combinação do segmento sênior da força de trabalho (idades 25 a 64) - que apresenta crescimento alto - com o segmento júnior (15 a 24 anos) - que registra taxas de crescimento muito baixas ou negativas - aponta para uma tendência de diminuição da pressão demográfica por empregos novos. A qualificação da futura força de trabalho torna-se componente imprescindível para um equilíbrio intergeracional, social e econômico, mais justo. Devido à TEE novos desafios emergem relacionados à expansão da população idosa. Se a atual transferência per capita do governo for mantida constante, a diferença entre receitas e despesas aumentará, provocando um insuportável déficit fiscal. A anunciada crise, causada pelo envelhecimento da população, e o atual sistema irracional previdenciário devem ser matéria de urgente discussão na sociedade brasileira. É extremamente importante aproveitar as oportunidades geradas pela TEE e se preparar para enfrentar os novos desafios dela decorrentes.
\end{abstract}

Palavras-chave: Envelhecimento. Transição da estrutura etária. Políticas públicas. Janela demográfica de oportunidades.

\section{Nota introdutória}

O termo Transição da Estrutura Etária (TEE), ${ }^{1}$ cunhado inicialmente por Pool (2000), engloba as mudanças produzidas pelo declínio da fecundidade e que se fazem sentir, depois, no tamanho relativo e absoluto das diversas coortes. Elas são mediadas pelas alterações nos padrões de sobrevivência e, em muitos casos, pelos fluxos migratórios. Este trabalho enfatiza a TEE extremamente rápida que o Brasil está experimentando em todas suas regiões. Esta simultaneidade ocorre num contexto regional caracterizado por história e cultura comuns e extremas desigualdades socioeconômicas e geográficas.

Este trabalho descreve, em primeiro lugar, a transição demográfica pela qual o Brasil está passando. Em segundo lugar, apresenta algumas perspectivas quanto aos gastos governamentais, dado o futuro

\footnotetext{
* Os autores agradecem a Andrea Simão pela colaboração, ao traduzir para o português a versão preliminar deste artigo, apresentado na XXV Conferência Internacional de População da União Intranacional para Estudos Científicos de População (Tours, França, Julho de 2005).

** Professora do Departamento de Demografia e pesquisadora do Cedeplar/Face/UFMG.

*** Professor do Departamento de Demografia e pesquisador do Cedeplar/Face/UFMG, com apoio do CNPq.

${ }^{1}$ Em inglês, o termo equivalente encontrado na literatura é "Age Structural Transition".
} 
padrão etário. Por fim, discute algumas das demandas sociais dos diferentes grupos etários em relação aos desafios gerados pela TEE e alternativas para enfrentá-los.

Muitos dos dados deste trabalho referem-se a previsões baseadas em pressupostos que, acreditamos, deixam pouco espaço para alteração significativa nas projeções. No caso do Brasil, a fecundidade dificilmente reverterá sua tendência; ao contrário, revisões recentes mostram que seus níveis têm sido sobreestimados. Com relação à mortalidade, em que pese a fragilidade dos dados sobre óbitos de adul- tos, assume-se que continuará declinando. Finalmente, a migração interna e a internacional podem levar à necessidade de alteração das previsões, mas, mesmo nestes casos, isto não causaria, provavelmente, mudanças substanciais nas projeções para os próximos qüinqüênios.

\section{A Transição da Estrutura Etária no Brasil}

Entre os anos 40 e 60, a população brasileira experimentou um declínio significativo na mortalidade, com fecundidade rela-

\section{GRÁFICO 1}

Pirâmide etária da população, por sexo

Brasil, América Latina e Caribe - 1950-2050
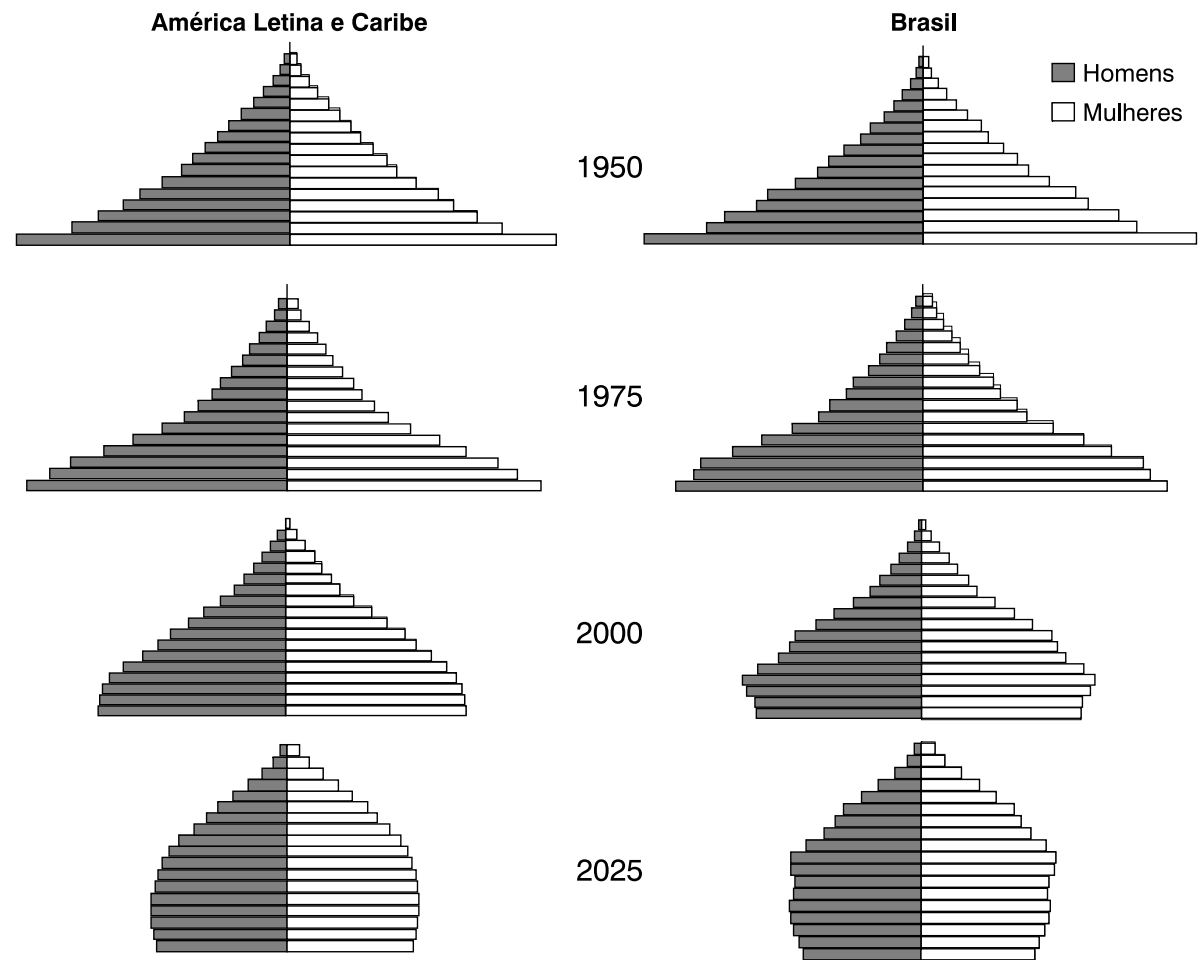

2000
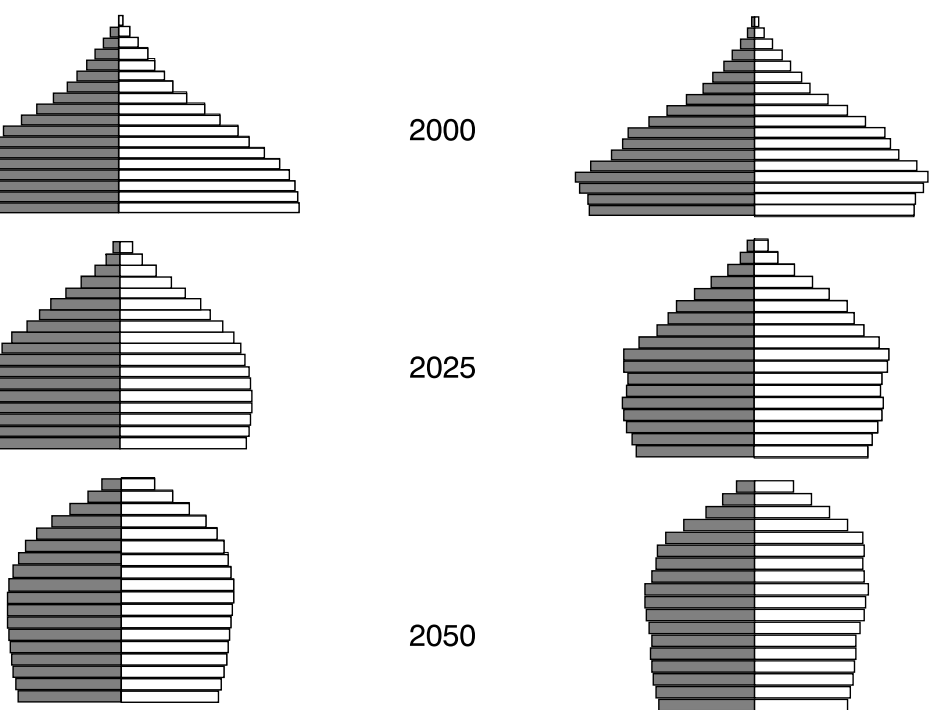

2025

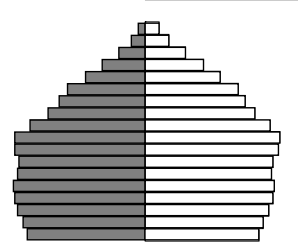

2050

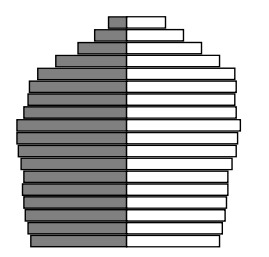

Fonte: Dados Brutos, Nações Unidas (2003). 


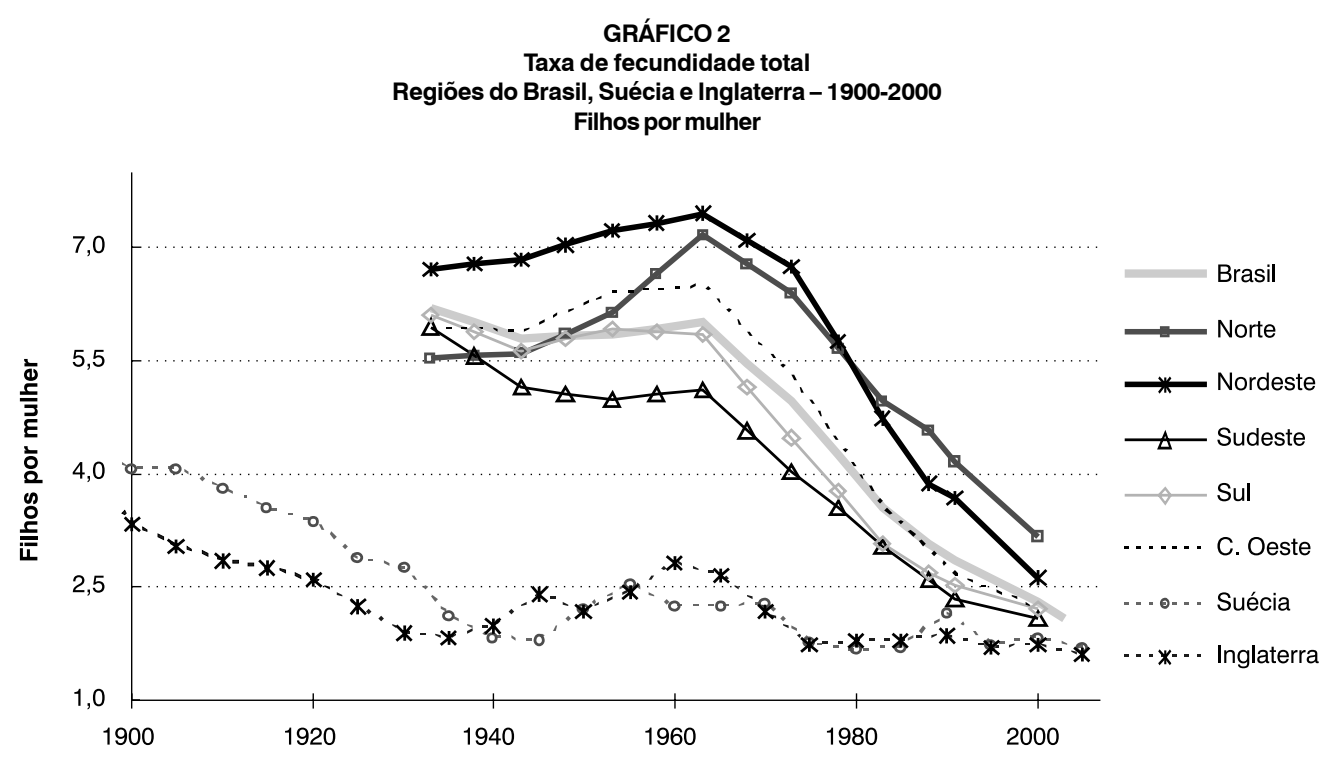

Fonte: Carvalho e Wong (1998); Frias e Carvalho (1996); Sawyer et al. (1999). IBGE. Pesquisa Nacional por Amostra de Domicílios - PNAD 2003.

tivamente constante. A partir da segunda metade da década de 60 , a rápida e sustentada redução da fecundidade desencadeou uma série de mudanças profundas na distribuição etária, tal como na maioria dos países da América Latina e do Terceiro Mundo (Gráfico 1).

O Gráfico 2 mostra o rápido declínio já mencionado da fecundidade, equivalente a $60 \%$, entre 1970 e 2000 . Por um lado, a magnitude dessa redução, num curto período de tempo, é surpreendente, se comparada com a experiência das nações desenvolvidas. Com efeito, sabe-se que a maior parte dos países europeus levou quase um século para completar sua transição da fecundidade. Suécia e Inglaterra, por exemplo, levaram cerca de seis décadas (aproximadamente de 1870 a 1930) para diminuir em torno de $50 \%$ seus níveis de fecundidade. O Brasil, por sua vez, experimentou um declínio similar em um quarto de século.

Por outro lado, a queda da fecundidade vem se mostrando generalizada em todo o território brasileiro. Embora desigualdades socioeconômicas e geográficas extremas tenham adiado o início desse processo nas regiões menos desenvolvidas do país, estimativas baseadas nos dados do Censo Demográfico de 2000 sugerem que níveis de reposição poderão ser alcançados pelas cinco regiões muito rapidamente. $O$ Nordeste, que tradicionalmente apresenta condições socioeconômicas menos favorecidas, teve uma redução de $50 \%$ na taxa de fecundidade total (TFT) num período de 15 anos (de 6,1 filhos por mulher, em 1980, para 3,0, em 1995). Uma redução similar foi observada no Norte. As duas regiões mais pobres e menos desenvolvidas experimentaram, nas duas últimas décadas do século passado, um declínio de fecundidade mais intenso do que o Sudeste (WONG, 2000).

A TFT nacional em 2005 estará, muito provavelmente, em torno do nível de reposição e sem perspectivas de retorno a patamares mais altos. ${ }^{2}$ De acordo com as estimativas das Nações Unidas, o Brasil apresentará o nível mais baixo de fecundidade da América do Sul, no período 2000-

\footnotetext{
${ }^{2}$ Estimativas a partir dos microdados das PNADs de 2003 e 2004 indicam que a TFT está em torno de 2,1 filhos por mulher.
} 
2005 (NAÇÕES UNIDAS, 2003). Além disso, estimativas de coorte indicam níveis de fecundidade das mulheres brasileiras mais jovens abaixo daquele de reposição, assim como níveis ainda mais baixos para as gerações subseqüentes (PERPÉTUO e WONG, 2003).

As mudanças na estrutura e no nível da mortalidade, com acentuada tendência de queda, começando nas regiões mais desenvolvidas no final dos anos 30 (CAMARGO e FRIAS, 2001), pouco afetaram, até agora, a estrutura etária brasileira. A probabilidade de um recém-nascido, em 1950, sobreviver até os 15 anos era inferior a $80 \%$; atualmente estima-se que essa probabilidade para as coortes nascidas no início deste século situe-se em torno de 95\%. Mudanças expressivas são observadas também nas idades adultas. Esperava-se que somente metade das coortes nascidas durante os anos 50 sobrevivesse até a idade de aposentadoria. Em contraste, tabelas de sobrevivência mais recentes (SAWYER et al., 1999) indicam que pelo menos $80 \%$ dos nascidos devam atingir a idade de 60 anos. Nas próximas décadas, o declínio da mortalidade no Brasil se concentrará, provavelmente, nas idades avançadas. Esse, sim, terá como efeito uma aceleração do processo de envelhecimento.

A migração internacional, que tem gerado saldos negativos, tem causado impacto pequeno sobre a estrutura etária nas décadas mais recentes, entre outras razões, devido ao volume populacional do país. Já a migração interna desempenha papel importante na definição das estruturas etárias regionais. Fluxos internos intensos nas idades economicamente ativas, o que significa seletividade por idade, contribuirão para exacerbar o processo de envelhecimento nas áreas de origem. É assim que Estados onde o início da transição da fecundidade começou mais tarde podem apresentar, hoje, estruturas etárias mais envelhecidas. ${ }^{3}$

\section{A estrutura etária}

Dentro do processo da TEE brasileira, a presença de crianças com menos de cinco anos reduziu-se de $15 \%$ para $11 \%$, entre 1970 e 1990. De maneira similar, a participação do grupo etário 5 a 9 anos declinou de $14 \%$ para $12 \%$. A proporção de crianças continuou diminuindo na década seguinte, alcançando, em 2000, tamanhos semeIhantes nos dois grupos etários (cada um com cerca de $9 \%$ do total da população). 0 formato acentuadamente piramidal começou, assim, a desvanecer, tendendo a uma forma retangular, o que é mais uma indicação do processo de envelhecimento (Gráfico 1). Os grupos mais velhos expandiram sua participação. A população de 60 anos ou mais, por exemplo, aumentou de $5,1 \%$, em 1970, para 8,6\%, em 2000.

\section{As relações intergeracionais}

Um primeiro enfoque, na análise das relações intergeracionais, pode ser feito considerando a participação de três grandes grupos etários (menos de 15 anos, de 15 a 64 anos e 65 anos e mais) na população total, em termos de Razões de Dependência (RD) e alguns índices, como o de Envelhecimento e o de Suporte (IE).

O Gráfico 3 mostra que a distribuição etária da população, ao longo de um período de 100 anos (1950 a 2050), mudará fortemente, o que se observa, mais nitidamente, na participação dos grupos etários extremos no total da população.

A Razão de Dependência (RD) e seus componentes (jovens, RDJ, idosos, RDI) definem, de uma maneira simples, a relação entre os diferentes grupos etários (Tabela 1). Até meados dos anos 70 , a participação da população em idade ativa (entre 15 e 64 anos) permaneceu basicamente constante e com valores extremamente altos. 0 contingente dependente (com menos de 15 e acima de 65 anos) era quase a metade

\footnotetext{
${ }^{3}$ Segundo o Censo de 2000, a proporção de pessoas com 60 anos ou mais na Paraíba, por exemplo, é semelhante à do Rio de Janeiro.
} 


\section{GRÁFICO 3}

Distribuição da população, por grupos etários

Brasil - 1950-2050

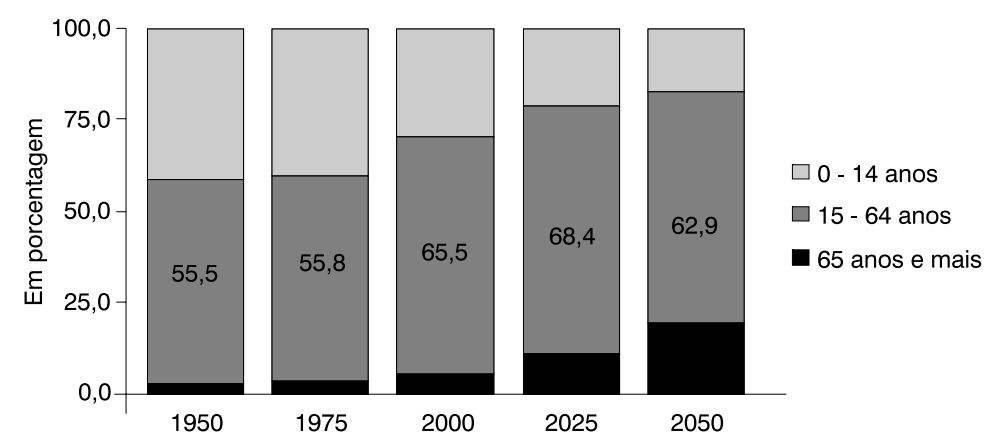

Fonte: Dados brutos, Nações Unidas (2003).

da população total, sendo que mais de $90 \%$ eram crianças com menos de 15 anos. A $\mathrm{RD}$ tem diminuído desde então e continuará declinando até 2025, segundo as projeções de população. Esta tendência de queda é uma mistura de duas tendências opostas: aumento no tamanho absoluto da população mais velha e diminuição, seguida de estabilização, do segmento com menos de 15 anos.

Como mostrado por Carvalho e Wong (1998), a RD total não retornará aos altos níveis registrados até meados da década de 70 , no século $X X$, embora a $R D I$ provavelmente duplicar-se-á entre 2000 e 2025 (ou quadruplicar-se-á, se for considerado o período 2000-2050).

O Índice de Envelhecimento, uma medida que considera apenas os dois grupos etários extremos, aqueles mais afetados no processo de envelhecimento, mostra a velocidade desse processo. Comparações feitas por Moreira (1997) apontam o Brasil entre os países com o ritmo mais acentuado de crescimento deste índice no futuro próximo. Em 2025, o Índice de Envelhecimento será, provavelmente, três vezes maior do que aquele observado em 2000. Na população brasileira haverá, então, mais de 50 adultos com 65 anos ou mais, por cada conjunto de 100 jovens menores de 15 anos. Em 2045, o número de pessoas idosas ultrapassaria o de crianças.

Considerando-se as relações entre os três grandes grupos etários, pode-se afirmar que estamos, atualmente, diante de uma janela de oportunidades, em termos demográficos, ou um bônus demográfico na terminologia de outros estudiosos. ${ }^{4}$ Com efeito, o país estará atingindo por volta de 2025 a mais baixa Razão de Dependência, pelo menos desde seu primeiro censo demográfico, em 1872. Isso, graças ao aumento da população nas idades ativas (em termos tanto absolutos quanto relativos), paralelamente ao rápido declínio da participação de crianças e jovens e ao ainda pequeno aumento, em termos absolutos, do peso relativo da população mais velha.

O Brasil, à frente da maioria dos países latino-americanos, está num estágio em que, de acordo com Behrman et al. (2001), serão observados alguns dos mais fortes $\mathrm{e}$ positivos efeitos da estrutura etária. A curto e médio prazos, o tamanho menor das gerações de crianças possibilita, em princípio, um maior retorno dos recursos nelas investidos. É de se esperar um aumento do investimento governamental per capita na educação, principalmente nos níveis fundamental e médio, em um contexto de diminuição sustentada do peso relativo -

\footnotetext{
${ }^{4}$ Ver, por exemplo, Bloom (1998).
} 
TABELA 1

Razão de Dependência e suas distribuições relativas e Índice de Envelhecimento

Brasil-1950-2050

\begin{tabular}{|c|c|c|c|c|c|c|c|}
\hline \multirow{3}{*}{ Anos } & \multicolumn{6}{|c|}{ Dependência } & \multirow{3}{*}{$\begin{array}{c}\text { Índice de } \\
\text { Envelhecimento }^{(4)}\end{array}$} \\
\hline & \multicolumn{3}{|c|}{ Razão (\%) } & \multicolumn{3}{|c|}{ Distribuição Relativa (\%) } & \\
\hline & Total $^{(1)}$ & Jovem $^{(2)}$ & $\operatorname{Idosa}^{(3)}$ & Total & Jovem & Idosa & \\
\hline 1950 & 80,3 & 74,9 & 5,4 & 100,0 & 93,3 & 6,7 & 7,2 \\
\hline 1975 & 79,2 & 72,2 & 7,0 & 100,0 & 91,2 & 8,8 & 9,6 \\
\hline 2000 & 52,7 & 44,8 & 7,9 & 100,0 & 85,0 & 15,0 & 17,6 \\
\hline 2025 & 46,2 & 30,6 & 15,6 & 100,0 & 66,2 & 33,8 & 51,0 \\
\hline 2050 & 59,1 & 27,6 & 31,5 & 100,0 & 46,7 & 53,3 & 114,3 \\
\hline
\end{tabular}

Fonte: Dados brutos, Nações Unidas (2003).

(1) Razão de Dependência (RTD) = RDJ + RDI.

(2) RDJ = população menor de 15 anos/população de 15-64 anos.

(3) RDI = população de 65 anos ou mais/população de 15-64 anos.

(4) Índice de Envelhecimento = população com 65 anos ou mais/ população com menos de 15 anos.

quando não do número absoluto - da população jovem e de aumento, ainda pequeno, do peso da população idosa (Gráfico 3). A RDI será significativamente mais alta somente a partir de 2020 . As crianças de hoje constituirão a força de trabalho do amanhã e enfrentarão crescentes razões de dependência de idosos. A conclusão lógica disto é que a sociedade necessita, vitalmente, investir na atual geração de crianças, particularmente nas áreas de saúde e educação. Não se trata, apenas, de garantir a melhoria da qualidade de vida dessas gerações, mas de sustentação, de forma equilibrada, de toda a sociedade, pois caberá às novas gerações, no médio prazo, como componentes da população em idade ativa, a responsabilidade por um bom desempenho da economia, mormente do ponto de vista da produção. Conseqüentemente, dependerá, também, das atuais gerações de jovens, no médio prazo, a garantia de uma vida digna às gerações de idosos. Ademais, é nesta fase que a sociedade deve se preparar, através de reformas institucionais na área da seguridade social, para conviver, no futuro próximo, com altas e sustentadas taxas de dependência de idosos.

\section{As taxas de crescimento}

O panorama da TEE, apresentado segundo os grandes grupos etários, pode ser mais bem compreendido considerando-se as taxas médias de crescimento anual ( $r$ ) entre 2000 e 2050, de grupos etários mais específicos (Tabela 2). As populações nos grupos de 0-14 e 15-24 anos, nascidas depois de 1975, portanto, durante o período de declínio da fecundidade, aumentarão durante a primeira metade deste século a taxas bem abaixo do valor médio da população total. Exceto no grupo etário 1524 anos entre 2000-2005, as taxas de crescimento serão negativas durante todo o período. De agora até meados do século, segundo as projeções das Nações Unidas, tanto a população alcançando a idade de entrada no sistema escolar quanto aquela completando a idade de introdução no mercado de trabalho crescerão, ano a ano, a taxas negativas.

Os grupos etários nos quais a força de trabalho mais se concentra (entre 25 e 64 anos) apresentarão, até 2015, taxas de crescimento bastante significativas, entre $2 \%$ e $1,6 \%$ ao ano, porém rapidamente declinantes, alcançando, entre 2045 e 2050, variação negativa. Finalmente, os grupos acima de 65 anos aumentarão a taxas positivas e altas durante todo o período: a população de 65 a 74 anos, a taxas crescentes e superiores a $3 \%$ ao ano até 2005 : e aquela com 75 ou mais anos de idade, a taxas significativamente superiores a $4 \%$ até 2030. Apenas a partir dessas datas passarão a ser sentidos, na variação do volume dos grupos etários correspondentes, os efeitos do declínio da fecundidade, iniciado décadas atrás.

É este padrão de crescimento diferenciado por idade (baixo no segmento jovem; 
TABELA 2

Taxa de crescimento média anual da população, por grupos etários Brasil-2000-2050

\begin{tabular}{lcccccc} 
& \multicolumn{3}{c}{ Brasil-2000-2050 } & Em porcentagem \\
\hline Períodos & Total & $\mathbf{0 - 1 4}$ anos & $\mathbf{1 5 - 2 4}$ anos & $\mathbf{2 5 - 6 4}$ anos & $\begin{array}{c}\mathbf{6 5 - 7 4} \text { anos } \\
\text { e mais }\end{array}$ \\
\hline $2000-2005$ & 1,2 & $0,32-$ & 0,38 & 2,26 & 3,04 & 4,84 \\
$2010-2015$ & 0,9 & $-0,26$ & $-0,65$ & 1,60 & 3,68 & 3,27 \\
$2020-2025$ & 0,6 & $-0,75$ & $-0,06$ & 0,73 & 4,50 & 4,90 \\
$2030-2035$ & 0,4 & $-0,41$ & $-0,73$ & 0,38 & 2,14 & 2,27 \\
$2045-2050$ & 0,1 & $-0,52$ & $-0,22$ & $-0,42$ & 46 \\
\hline
\end{tabular}

Fonte: Dados brutos, Nações Unidas (2003).

alto na população em idade ativa até 2025; altíssimo no contingente de idosos) que produz, necessariamente, a mudança na estrutura etária. E é para esta complexa dinâmica populacional que os formuladores de políticas públicas devem atentar.

\section{O tamanho da população brasileira}

Entre 2000 e 2020, cerca de 38 milhões de pessoas serão adicionadas à população total. Apesar disso, entre os jovens e mesmo em certos segmentos da população adulta, taxas de crescimento negativas prevalecerão. Durante esse período, o tamanho da população abaixo de 25 anos deverá diminuir em cerca de 5 milhões. Além disso, o grupo de 15 a 35 anos (que atualmente inclui as mulheres responsáveis por mais de $90 \%$ dos nascimentos) enfrentará taxas de crescimento negativas por todo o período 2010-2050. Com isso, o número de nascimentos, que na virada do século já experimentou queda absoluta, poderá continuar declinando, mesmo se a taxa de fecundidade permanecer constante. ${ }^{5}$

\section{A população em idade de trabalhar}

O contingente responsável pela produção econômica centra-se, principalmente, no grupo etário de 15 a 64 anos e pode ser desagregado em dois grandes subgrupos.

Primeiro, considere-se a população que, em princípio, corresponderia à mãode-obra sênior (25 a 64 anos: 75,5 milhões em 2000). Sua alta taxa de crescimento (Tabela 2) implica um incremento anual entre 2 e 1,5 milhões de pessoas, ao longo da primeira década deste século. Este importante subgrupo, representando, em 2000 , em torno de $45 \%$ da população total, deverá continuar a crescer até 2045. A população neste subgrupo registra, normalmente, altas taxas de atividade e é composta pelos contribuintes fiscais mais expressivos da força de trabalho.

Segundo, tome-se a população que abarcaria o segmento júnior de mão-deobra (idades entre 15 e 24 anos: 34,3 miIhões em 2000). Este subgrupo, em que estariam, majoritariamente, aqueles entrando na força de trabalho pela primeira vez, terá taxas negativas de crescimento a partir do qüinqüênio 2005/2010. Uma fração importante (aqueles de 15 a 19 anos) dedicase, exclusiva ou concomitantemente, a estudar. A outra (20 a 24 anos) estará, provavelmente, no seu primeiro emprego ou à sua procura.

Se a população em idade ativa é relativamente jovem, o desemprego tende a ser mais elevado, diminuindo à medida que a estrutura etária envelhece (BEHRMAN et al., 2001). Até recentemente, o tamanho do grupo júnior, no Brasil, aumentou, em números absolutos, muito rapidamente (Gráfico 4).

Quando o número de jovens cresce aceleradamente, ao entrar no mercado de trabalho, há forte pressão na economia, pela necessidade de geração de novos empregos, com o risco de aumentar a instabi-

${ }^{5}$ O número anual de registros de nascimentos diminuiu de 4,2 milhões para 3,8 milhões entre o biênio 1999/2000 e 2001/2002 (IBGE). Estes valores encobrem registros atrasados, no entanto, dados altamente confiáveis de UFs como São Paulo, Santa Catarina ou Rio Grande do Sul confirmam esta acentuada diminuição (Sinasc/Datasus dos anos 2000 em diante). 
GRÁFICO 4

População de 15 a 19 e 20 a 24 anos e razões intragrupos em idade economicamente ativa

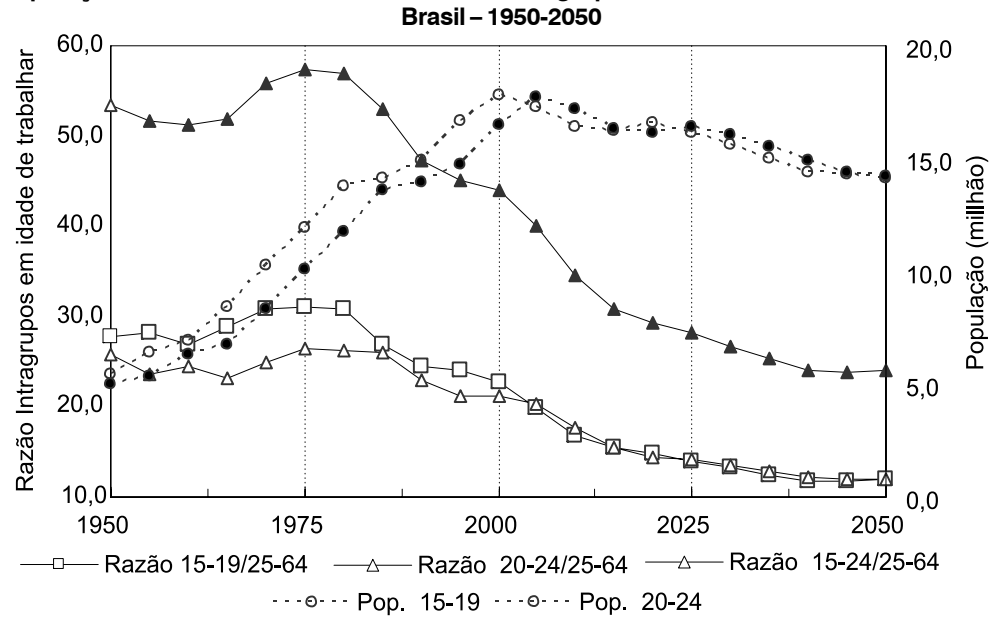

Fonte: Dados Brutos, Nações Unidas (2003).

GRÁFICO 5

Razões intra-idade ativa

Regiões do Brasil - 2000-2040

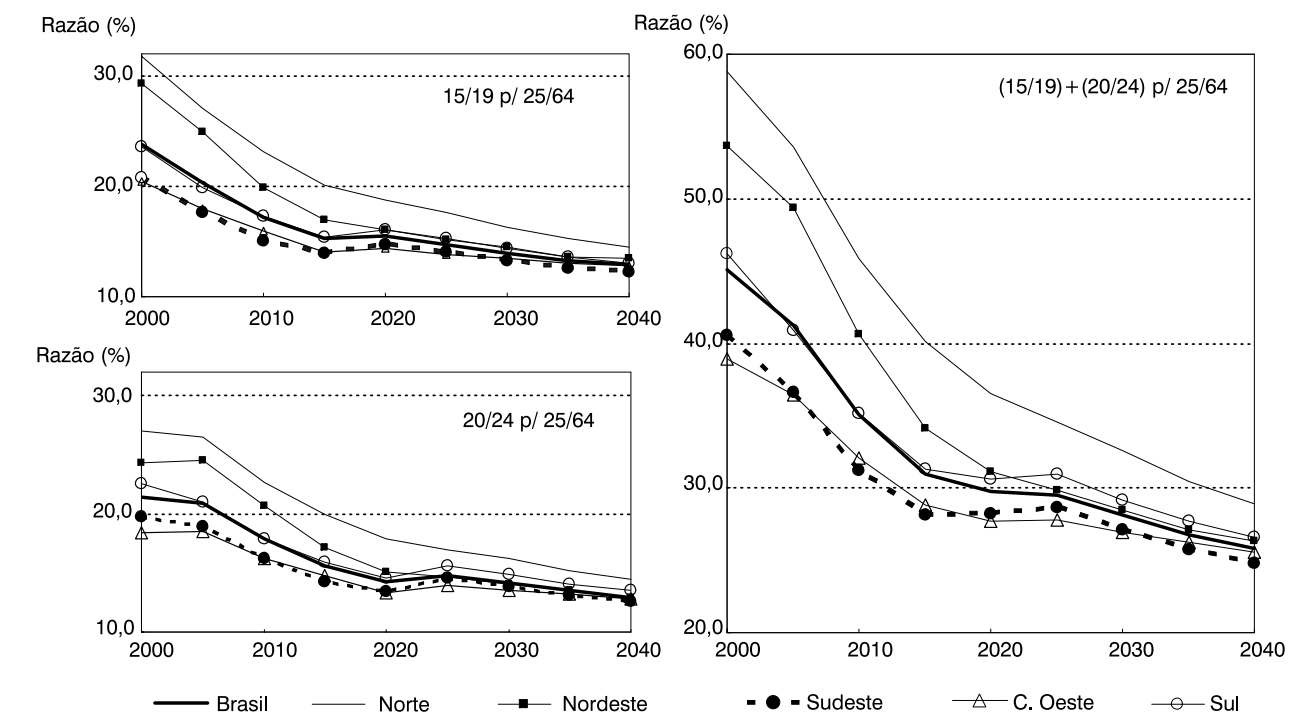

Razão (\%)

Fonte: Estimativas geradas usando projeções feitas por Sawyer et al. (1999).

lidade social ou econômica que o aumento do desemprego provoca. ${ }^{6}$ A razão entre a mão-de-obra júnior e a sênior é um indicador da pressão pela necessidade de novos empregos. No caso do Brasil, este quociente começou a apresentar uma tendência de declínio durante os anos 80 (Gráfico 4), que se acentuará nas próximas décadas devido

\footnotetext{
${ }^{6}$ Muniz (2003) observou esta relação, particularmente, entre homens jovens (15 a 19 anos) nas áreas metropolitanas, onde taxas de crescimento ainda mais altas são causadas por migrações internas. Esta tendência demográfica é, provavelmente, um dos fatores que tornou mais difícil resolver o problema do desemprego nos anos 90 .
} 
ao crescimento negativo da população jovem.

Com a disseminação da TEE pelo país, a mesma tendência é observada em todas as regiões brasileiras, independentemente de seu nível de desenvolvimento econômico (Gráfico 5). Nas Regiões Norte e Nordeste, onde mais recentemente iniciou-se a TEE e que, como se sabe, são menos desenvolvidas, o declínio destas razões será mais acentuado.

Embora a transição de uma população jovem para uma mais envelhecida possa, inicialmente, impulsionar as perspectivas de crescimento econômico, devido à redução, dentro da população em idade ativa, da proporção de jovens, a maior proporção, na população total, daquela em idade ativa, como um todo, poderá constituir uma ameaça, se as políticas adotadas não forem adequadas (BEHRMAN et al., 2001). De um lado, poderá haver outra janela de oportunidades: o crescimento positivo no grupo etário que inclui trabalhadores sênior, que normalmente possuem maiores taxas de emprego do que a mão-de-obra júnior, ${ }^{7}$ implica, também, maiores contribuições fiscais. De outro lado, o desafio será mais difícil se a força de trabalho sênior não for preparada ou estiver subempregada, o que é o caso, principalmente, nas regiões brasileiras menos desenvolvidas. Nestas circunstâncias, o bônus demográfico gerado pela menor pressão por novos postos de trabalho pode perder sua eficácia inicial.

\section{A sustentação fiscal da TEE no Brasil: receitas e despesas governamentais relacionadas à idade}

Apesar do bom desempenho dos indicadores sociais durante a maior parte da segunda metade do último século, o Brasil ainda continua subdesenvolvido e com uma das piores distribuições de renda do mundo (IPEA, 2005). Políticas públicas têm buscado a superação de tais disparidades. A maior parte delas tem estreita relação com a idade da população e precisa levar em conta o atual processo de TEE.

Por um lado, programas materno-infantis, por exemplo, podem ser qualitativamente melhorados, uma vez que o número de beneficiários está diminuindo (em termos relativos e, freqüentemente, absolutos). Por outro lado, mais pressão surgirá de novas necessidades. As demandas, por exemplo, dos idosos poderão se tornar tão grandes que recursos de outros programas precisarão ser alocados para este segmento populacional.

Para avaliar a magnitude destas mudanças anunciadas, uma análise dos gastos governamentais é apresentada.

Sobre receitas e despesas governamentais relacionadas à idade

Um exercício contábil das transferências governamentais (receitas e despesas), tomando-se como base impostos discriminados por idade, para os anos 90 , revela, como esperado, que a origem dos recursos que alimentam o financiamento de gastos públicos concentra-se nas idades centrais da população economicamente ativa (TURRA, 2001). O perfil etário dos impostos, estimado pelo autor, mostra que as transferências de recursos da população entre 30 e 49 anos eram cerca de US\$2.000 per capita por ano, em 1996, estando o ponto modal entre as idades de 40 a 49 anos (Gráfico 6). ${ }^{8}$

As despesas governamentais per capita relacionadas à idade da população, quando comparadas à receita, como estimado por Turra (2001), são maiores e com diferente padrão por idade. Volumes

\footnotetext{
${ }^{7}$ Resultados de Behrman et al. (2001) mostram que, se a estrutura etária da população é relativamente jovem, a taxa de crescimento da população em idade economicamente ativa tende a ultrapassar a taxa de crescimento de acumulação de capital. Mais tarde, quando as coortes mais jovens - menores em tamanho - atingirem a idade economicamente ativa, o capital por trabalhador tende a aumentar.

${ }^{8}$ Contabilidade realizada por Turra (2000) mostra que os impostos relacionados ou não com a idade somaram US $\$ 218$ bilhões, o equivalente a $28 \%$ do Produto Nacional Bruto de 1996. Os valores aqui apresentados desconsideram itens não relacionados diretamente com a idade, tais como segurança pública, transporte, pesquisa e defesa.
} 
GRÁFICO 6

Transferências governamentais per capita, por grupos etários Brasil - 1995

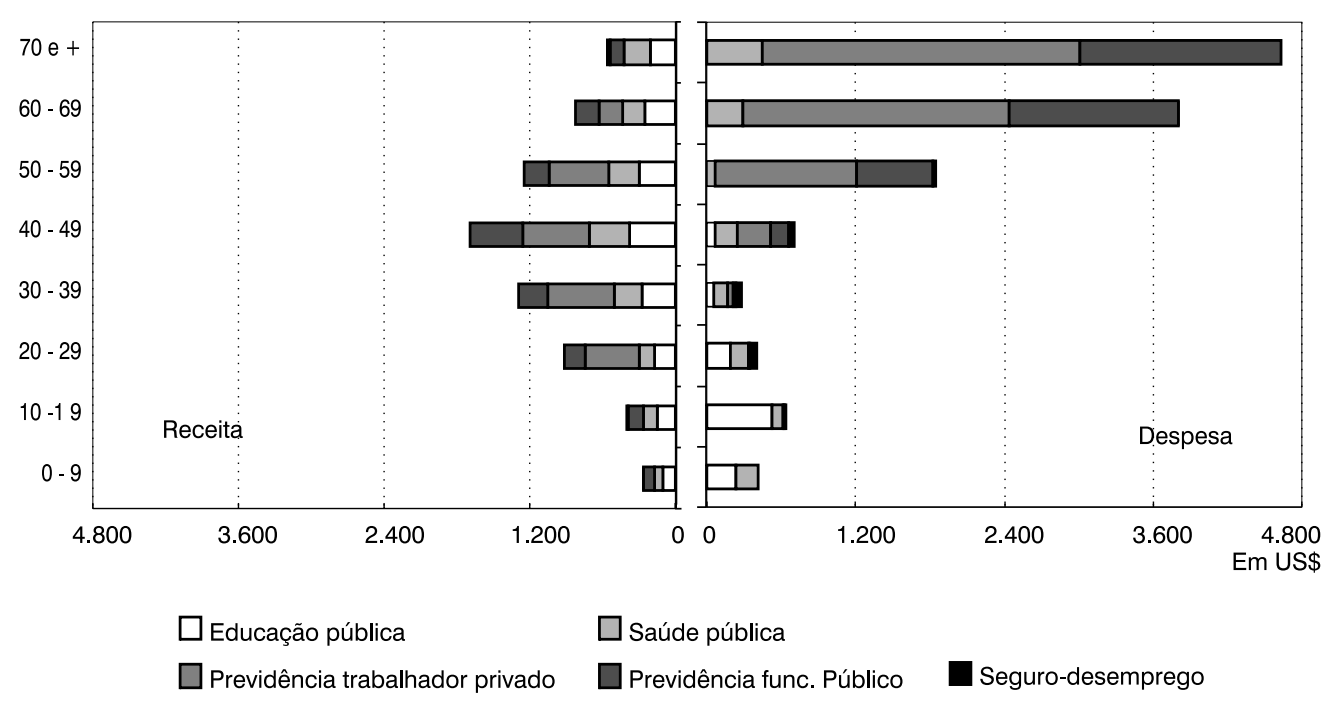

Fonte: Elaborado a partir dos dados de Turra (2001).

menores destinam-se às pessoas mais jovens, nas quais a maioria dos gastos é alocada na educação. O gasto per capita mais baixo dá-se no grupo etário entre 30 e 39 anos. Após esta idade, as transferências governamentais aumentam exponencialmente e direcionam-se, quase exclusivamente, para a saúde, pensões e aposentadoria de funcionários públicos e trabaIhadores do setor privado. Depois da idade 60 , os gastos anuais ultrapassam US\$ 4.000 per capita, dez vezes o equivalente transferido para uma criança com menos de dez anos. Proporções semelhantes são encontradas apenas em países desenvolvidos (TURRA, 2001). No Brasil a maior parte dos recursos vai para as aposentadorias, com peso desproporcional daqueles destinados aos servidores públicos. Uma fração relativamente pequena é destinada à saúde pública. O Brasil, certamente, difere da maioria dos países desenvolvidos, neste aspecto.

Dada a estrutura etária das transferências governamentais per capita, tem havido, de acordo com Turra, um ganho econômico significativo, devido ao bônus demográfico. Parte desse ganho teria sido a taxa de crescimento relativamente alta da força de trabalho. Entretanto, a janela demográfica de oportunidades não é permanente, existindo desafios emergentes a serem enfrentados, sem o que a sociedade não se beneficiará das oportunidades oferecidas pelo padrão demográfico brasileiro.

Perspectivas das receitas e despesas governamentais por idade

Uma simulação simples, usando os dados anteriormente mencionados, mostra que as futuras despesas governamentais, provavelmente, crescerão proporcionalmente mais do que a receita (impostos), devido à TEE. Resultados globais desta simulação estão na Tabela 3 e valores desagregados por grupos de idade são apresentados no Gráfico 7.

O exercício é feito para os anos de 2000 , 2025 e 2050, com o pressuposto de que as transferências per capita (receitas e despesas) permaneçam constantes por idade. Num sentido amplo, isto implica transferências individuais constantes para 
o governo e valores constantes da oferta per capita de serviços públicos básicos, tais como saúde, educação e previdência social. Certamente, poderiam ser utilizadas hipóteses mais complexas para prever as receitas e despesas governamentais por idade. Entretanto, presume-se constante o valor per capita porque a ênfase está nas conseqüências das mudanças no padrão etário sobre o equilíbrio fiscal do Estado.

A Tabela 3 mostra que a razão entre receita e despesa governamental por idade $(R / D)$ era próxima a 1,0 em 2000. O padrão por idade da receita difere, significativamente, daquele das despesas. Estas últimas são alocadas, principalmente, na população de 50 anos ou mais, com extrema concentração entre aqueles com 60 anos ou mais; as receitas têm origem, mormente, na população em idade ativa, com concentração naquela entre 30 e 49 anos (Gráfico 7).
Em 2025, a R/D $(0,84)$ seria significativamente menor do que no cenário de 2000. Enquanto, entre 2000 e 2025, a receita se elevaria $33 \%$, em função da alta taxa de crescimento da população em idade ativa, como mencionado anteriormente, as despesas aumentariam ainda mais (aproximadamente $60 \%$ ), devido ao alto crescimento da proporção da população idosa. Como conseqüência, o padrão etário dos gastos governamentais variaria drasticamente. Aqueles com 60 anos ou mais passariam a receber metade do total da receita governamental. Isto é esperado, devido ao avanço do envelhecimento. Entretanto, o padrão etário das receitas permaneceria aproximadamente constante.

O cenário em 2050 seguiria a tendência iniciada em torno de 2025. A R/D cairia para, aproximadamente, 0,5. Entre 2025 e 2050, as receitas aumentariam um pouco (10\%),

TABELA 3

Simulação das receitas e despesas, segundo grupos etários Brasil-2000-2050

\begin{tabular}{|c|c|c|c|c|c|c|}
\hline \multirow{3}{*}{ Grupos etários } & \multirow{2}{*}{\multicolumn{2}{|c|}{2000}} & \multirow{2}{*}{\multicolumn{2}{|c|}{2025}} & \multicolumn{2}{|c|}{ Em milhões de US\$ } \\
\hline & & & & & \multicolumn{2}{|c|}{2050} \\
\hline & Receitas & Despesas & Receitas & Despesas & Receitas & Gastos \\
\hline $0-9$ anos & $8.904,2$ & $13.521,2$ & $8.328,02$ & $12.646,3$ & $7.178,9$ & $10.901,2$ \\
\hline $10-9$ anos & $14.313,1$ & $22.421,5$ & $13.293,4$ & $20.824,2$ & $11.333,5$ & $17.754,0$ \\
\hline $20-29$ anos & $29.172,8$ & $12.258,8$ & $30.311,4$ & $12.737,3$ & $26.773,6$ & $11.250,6$ \\
\hline 30-39 anos & $35.095,0$ & $7.469,3$ & $44.653,3$ & $9.503,6$ & $39.453,2$ & $8.396,8$ \\
\hline $40-49$ anos & $34.683,6$ & $14.033,8$ & $49.777,2$ & $20.141,1$ & $53.302,5$ & $21.567,5$ \\
\hline $50-59$ anos & $16.021,5$ & $23.184,1$ & $29.975,2$ & $43.375,9$ & $37.073,1$ & $53.646,9$ \\
\hline $60-69$ anos & $6.770,6$ & $30.131,0$ & $13.913,2$ & $61.917,7$ & $23.941,6$ & $106.547,2$ \\
\hline 70 anos e mais & $3.112,6$ & $25.534,7$ & $6.612,7$ & $54.247,7$ & $18.355,9$ & $150.583,7$ \\
\hline Total & $148.074,0$ & $148.554,5$ & $196.864,5$ & $235.393,6$ & $217.412,3$ & $380.648,0$ \\
\hline $\begin{array}{l}\text { \% das receitas } \\
\text { alocadas à pop. } \\
\text { de } 60 \text { anos e mais }\end{array}$ & \multicolumn{2}{|c|}{37,47} & \multicolumn{2}{|c|}{49,35} & \multicolumn{2}{|c|}{67,55} \\
\hline \multirow[t]{3}{*}{$\mathrm{R} / \mathrm{D}^{(1)}$} & \multicolumn{2}{|c|}{0,99} & \multicolumn{2}{|c|}{0,84} & \multicolumn{2}{|c|}{0,57} \\
\hline & \multicolumn{2}{|c|}{ 2000-2025 } & \multicolumn{2}{|c|}{ 2025-2050 } & \multicolumn{2}{|c|}{ 2000-2050 } \\
\hline & Receitas & Despesas & Receitas & Despesas & Receitas & Gastos \\
\hline Variação relativa (\%) & 32,9 & 58,5 & 10,44 & 61,71 & 46,8 & 156,2 \\
\hline Aumento anual (\%) & 1,14 & 1,84 & 0,40 & 1,92 & 0,77 & 1,88 \\
\hline
\end{tabular}

Fonte: Estimativas a partir dos dados produzidos por Turra (2001).

(1) Razão entre receitas e despesas governamentais relacionadas à idade. 
GRÁFICO 7

Receitas (impostos) e despesas governamentais totais, por grupos etários Brasil -2000-2050
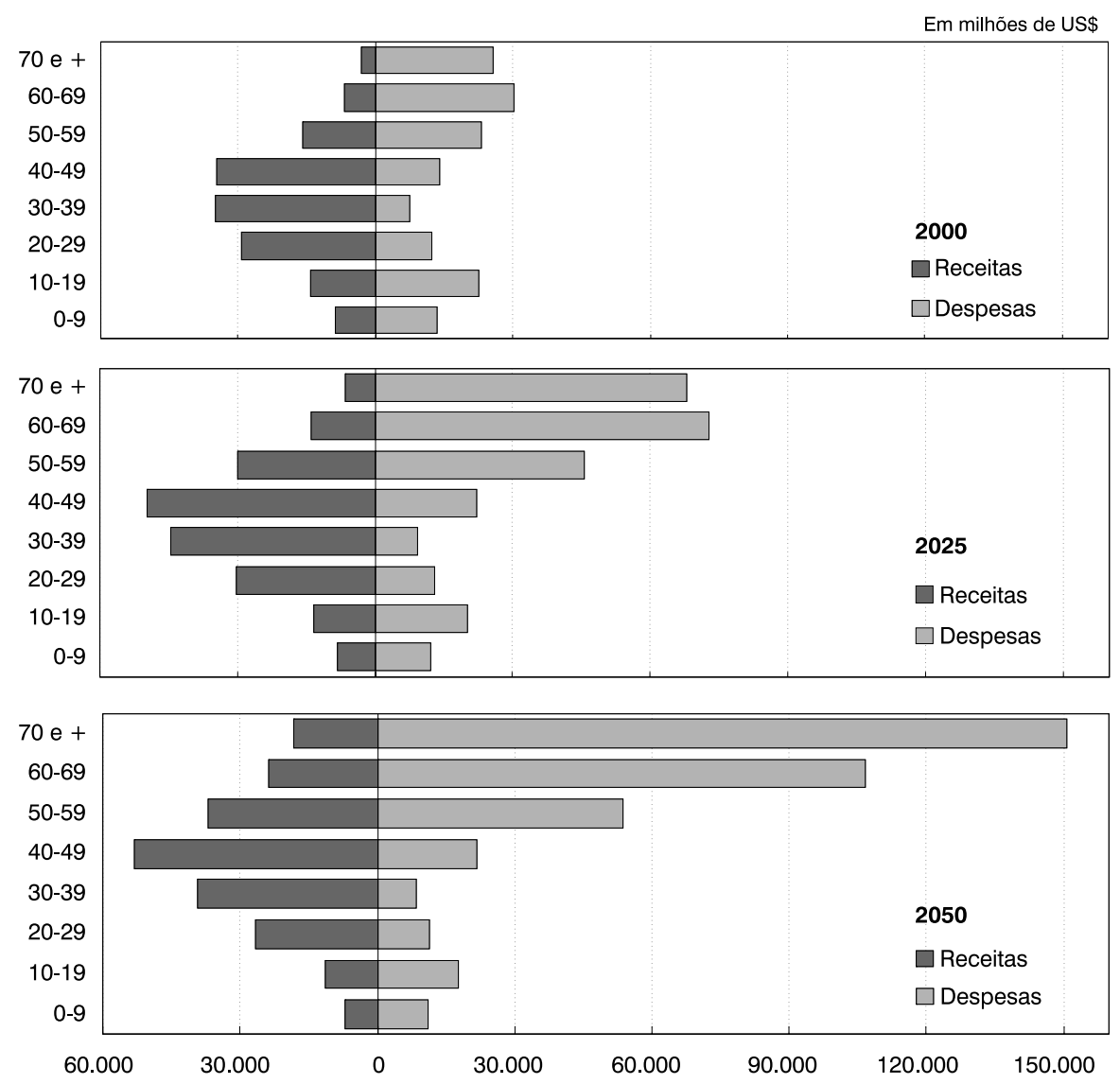

Fonte: Estimativas a partir dos dados produzidos por Turra (2001).

pois a população em idade ativa (os principais contribuintes) continuará a crescer. Já no caso das despesas, a expansão seria superior a $60 \%$, em função do rápido aumento na população idosa. Isto, claro, afetará o déficit público. Enquanto o padrão etário das receitas permanecerá quase o mesmo, o padrão etário das despesas exacerbaria a tendência descrita do período anterior. Em termos absolutos, haverá risco de se alocar menos recursos financeiros governamentais para a população jovem, já que se espera que este segmento apresente crescimento negativo até o final da primeira metade deste século. Aproximadamente $70 \%$ das despesas gover- namentais relacionadas à idade destinarse-iam à população com 60 anos ou mais.

Em resumo, se as atuais receitas e despesas governamentais per capita continuarem constantes, a diferença entre receitas e despesas expandir-se-á velozmente, com o risco de tornar insustentável o débito fiscal.

\section{Políticas sociais e econômicas relacionadas à idade}

Nesta seção são consideradas as conseqüências da transição etária sobre as demandas sociais de grupos selecionados - crianças, população em idade de trabalhar 
e idosos -, bem como discutidas alternativas para o desenvolvimento sustentável.

Nesta discussão, cabe uma palavra de cautela. A diminuição do número ou do peso relativo das pessoas em grupos etários que são objeto de políticas públicas específicas propicia, em princípio, um melhor atendimento da demanda. No entanto, o próprio processo de mudanças socioeconômicas, dentro do qual se dá a transição da fecundidade, pode mudar as características da demanda, minimizando ou anulando essa vantagem inicial. Um exemplo típico é a demanda por educação infantil (creche e maternal), que pode aumentar desproporcionalmente à variação do número de crianças, devido, entre outras razões, ao crescimento da participação feminina na força de trabalho e à difusão de atitudes modernas, incentivando as crianças a interagirem, além da fronteira de seus lares.

\section{População infantil}

A população infantil, embora apresentando pequenas oscilações no tamanho das novas coortes, terá taxa de crescimento abaixo de zero, tal como ilustrado anteriormente na Tabela 2. Políticas públicas voltadas para a infância poderiam beneficiar muito mais as novas gerações, devido às condições favoráveis do lado da demanda.

Dois aspectos serão aqui considerados: nutrição e educação.

- Nutrição infantil

Condições para melhoria nos padrões nutricionais surgem durante a TEE. $O$ declínio da fecundidade no Brasil teve, como conseqüência, não somente o surgimento de famílias menores, mas também a ampliação dos intervalos de nascimentos (BEMFAM, 1997), aumentando as chances de melhorar os níveis de nutrição infantil. Peliano (1990) constatou que houve melhoras nutricionais significativas durante os anos 80, quando o declínio da fecundidade já houvera avançado. Entretanto, uma sociedade só pode aproveitar, inte- gralmente, o dividendo demográfico para resolver ou reduzir problemas sociais se um planejamento adequado for aplicado no momento certo. Ainda há populações vulneráveis nestas idades. Silva et al. (2001) encontraram alta prevalência de anemia entre crianças com idade inferior a 36 meses, em creches públicas de Porto Alegre, cidade com padrão de vida relativamente alto. Há, ainda, sem dúvida, a necessidade de intervenções para superar este problema. Seguramente, isto é mais fácil (ou menos difícil) com coortes de menor tamanho.

No transcorrer da transição da fecundidade, podem surgir outros fatores que anulem os benefícios deste particular momento demográfico. A modernização costuma encorajar, por exemplo, a ocidentalização de hábitos nutricionais; o país está, agora, num estágio de transição nutricional no qual começa a aparecer a obesidade. A prevalência de sobrepeso entre a população adulta, em 2002-2003, era relativamente alta nas cinco regiões, nas áreas urbana e rural e em todos os estratos socioeconômicos (IBGE, 2004, p. 49). Há evidências de que, independentemente do nível de renda, a preferência por refeições processadas - as denominadas fast-food está presente em cidades tanto do Norte como do Sudeste. ${ }^{9}$ Doyleand e Feldman (1997) apontam para a necessidade de envolver crianças e pais em campanhas de educação nutricional sobre preferências alimentares e de evitar o risco de doenças crônicas. Esta é uma recomendação óbvia que, não obstante, está longe de ser implementada. Outro exemplo encontra-se no padrão etário de declínio da fecundidade, com aumento da participação da gravidez na adolescência. Sabe-se que mães adolescentes estão mais sujeitas a dar à luz crianças de baixo peso. Fatores socioculturais, tais como pobreza e privação social, bem como fatores biológicos e nutricionais durante a gravidez, podem ser determinantes importantes deste fenômeno (GAMA et al., 2001). Programas educacionais de baixo custo, dirigidos à população jovem,

${ }^{9}$ Veja, por exemplo, Doyle e Feldman (1997); Aquino e Philippi (2002); Barreto e Cyrillo (2001). 
podem ser planejados com mais chances de sucesso, agora que este segmento populacional apresenta taxas de crescimento abaixo de zero.

\section{- População em idade escolar}

O tamanho das populações com menos de 15 anos, muito provavelmente, diminuirá até 2050 , embora os vários subgrupos etários envolvidos experimentem taxas de crescimento oscilantes. Obviamente, como foi o caso dos países do sul e sudeste asiático, a diminuição oferecerá oportunidades demográficas claras para se chegar a uma educação, nos níveis fundamental e médio, universal e de qualidade. Para atingir este objetivo, um novo modelo educacional, com flexibilidade suficiente para permitir que sejam antecipadas as variações de demanda geradas pelas oscilações populacionais, torna-se essencial.

O Brasil apresenta uma singular oportunidade, favorável para implementar uma política educacional que supere as deficiências do sistema, tais como cobertura insatisfatória, altas taxas de repetência e evasão, baixa qualidade de ensino, para o que os problemas relacionados aos baixos salários e à pouca qualificação dos professores têm que ser, necessariamente, sanados. Pesquisa feita pelo Inep (2004) adverte para uma escassez aguda de professores já no curto prazo se as condições de trabaIho, principalmente salários, não melhorarem (UNESCO, 2005).

Poder-se-ia pensar que a infra-estrutura física e de recursos humanos, necessária para atender a toda a demanda por educação fundamental, já esteja praticamente pronta, diante do atual grau de cobertura, quase completa, e do declínio do número de jovens. No entanto, além da pouca qualificação do corpo docente e das condições precárias de muitas das instalações escolares, há de se levar em conta que se torna imprescindível oferecer aos jovens educação em tempo integral, ao invés de em apenas um turno, como se faz atualmente na quase totalidade das escolas brasileiras. Para tal, é necessário um esforço enorme da sociedade, dentro de um "projeto de Nação", que, no entanto, torna- se mais plausível no contexto da transição da fecundidade.

À medida que a pressão advinda de crianças entrando na escola diminui, ou mesmo desaparece, todos aqueles já matriculados beneficiam-se da TEE. Riani (2001) mostra que a redução da coorte em idade escolar, em 1990, tornou possível, além do aumento da cobertura, a melhoria na qualidade e na eficiência do sistema educacional. No entanto, é provável que os avanços ora em curso tenham se dado mais devido ao lado da demanda - menor número de jovens do que da oferta.

A simulação apresentada nas páginas anteriores mostra que se os gastos governamentais per capita, relacionados à idade, forem mantidos constantes, resultarão, num futuro próximo, em menor proporção de recursos alocados à educação devido à redução da população em idade escolar, em termos tanto relativos quanto absolutos. $\mathrm{O}$ déficit fiscal rapidamente crescente, causado, como visto, pela diferença entre receitas e despesas governamentais relacionadas à idade, fortalecerá os argumentos para que o investimento público governamental no sistema educacional não seja aumentado. Entretanto, a atual TEE brasileira representa uma oportunidade ímpar para superar um dos principais problemas do país, razão pela qual deveria se lutar pela expansão do sistema educacional em vez de reduzi-lo devido à diminuição na demanda. A janela de oportunidades resultará em aumento da oferta de capital humano de alta qualidade, somente se investimentos apropriados forem realizados (BIRDSALL e SINDING apud NAVANEETHAM, 2001).

Um problema adicional, apesar dos avanços na cobertura da educação básica brasileira, é o enorme déficit em termos de educação secundária e universitária, isto sem considerar a qualidade. Adicionalmente, a economia brasileira poderia ter um desempenho melhor se políticas para capacitação técnica fossem reforçadas. De acordo com Bowman (1987), onde existe certa diversidade na atividade econômica - como é o caso brasileiro - há mais espaço para progressos em educação alternativa. Não foi por acaso que programas educa- 
cionais envolvendo o governo e os setores industriais e tecnológicos desenvolveramse muito em países que estão, atualmente, à frente dos desafios econômicos - como Coréia do Sul e Malásia, por exemplo. Assim, o ensino técnico após o término da educação básica deve ser de suma importância e uma alternativa neste início de século. O Brasil deveria se espelhar na transição dos países da Ásia Ocidental, onde a população jovem, cuja alta qualificação foi obtida através de educação técnica, contribuiu, significativamente, para o seu progresso (BOWMAN, 1987:88-89). A qualidade e os níveis de escolaridade alcançados aconteceram de forma tal que a sucessão de coortes jovens menores em tamanho não representou problemas para a sua força de trabalho.

\section{A população em idade economicamente ativa}

A TEE brasileira envolve, como já mostrado, uma população em idade ativa crescente até 2025, como proporção da população total do país, quando alcançará seu valor máximo (em torno de 69\%). A partir de 2025 declinará lentamente, atingindo 63\% em 2050 (Gráfico 3). O primeiro e mais evidente desafio é a geração de empregos que acompanhe esse crescimento. Dentro deste grande grupo, entretanto, o segmento júnior (população de 15 a 24 anos) já está entrando num período de crescimento negativo, enquanto a força de trabalho sênior continua crescendo. Do ponto de vista demográfico, esta composição representa um bônus se, como mencionado, a força de trabalho estiver empregada adequadamente. $\mathrm{O}$ crescimento positivo da força de trabalho sênior nestas condições significa maior capacidade de poupança, maior receita governamental e, conseqüentemente, maior capacidade para financiar programas públicos.

No Brasil, uma parte importante da população trabalhadora jovem está na escola. Nas idades entre 15 e 19 anos, dois terços dos jovens freqüentam a escola, estando ou não trabalhando; destes, aproximadamente metade, geralmente mais pobre, é constituída de trabalhadores em tempo integral. Silva Leme e Wajnman (2000) encontraram que, entre aqueles que trabaIhavam e freqüentavam escola simultaneamente, uma porção significativa tinha retornado à escola depois de se tornar economicamente ativa. Isto pode ser um sinal de pressão por qualificação adicional que gere maior produtividade. Assim, novamente, os formuladores de políticas deveriam aproveitar a conjuntura oferecida pela TEE e privilegiar a formação de recursos humanos, com particular atenção às gerações mais novas.

Existem razões adicionais para focalizar a mão-de-obra júnior. Se, por um lado, a taxa de crescimento negativa deste segmento indica menor pressão por geração de empregos e, no futuro próximo, sinaliza outra janela de oportunidades, por outro, pode também ser motivo de alarme. Chesnais (2004) argumenta que este grupo também é muito importante para o mercado de consumo, dado que seus membros estão no estágio de formação de família, quando surgem demandas por moradia, casas, móveis, automóveis e outros bens duradouros. Assim, a diminuição do tamanho deste grupo pode se tornar um fator igualmente negativo se levar a um declínio da demanda agregada da economia.

Como visto, o aumento do peso relativo da força de trabalho sênior favorece, em princípio, o crescimento econômico, devido à sua maior capacidade de poupança (LINDH e MALMBERG, 1999). Este grupo apresentará taxas de crescimento altas nas próximas décadas. Como no caso de Cingapura, analisado por Navaneetham (2001), o Brasil poderá usar esta oportunidade para aumentar sua capacidade de poupança, o que é imprescindível para que se acelere o crescimento econômico. No entanto, os benefícios irão se materializar somente se o ambiente socioeconômico for favorável à poupança e, sobretudo, se for aumentado, significativamente, o nível de emprego e restabelecido o equilíbrio fiscal. Isto é, claramente, um grande desafio para o país. Behrman et al. (2001) explicam que, na América Latina, o processo de enveIhecimento não coincidiu, até agora, com 
aumentos na poupança, em contraste com o que aconteceu nos países asiáticos.

Como a razão de dependência idosa estará, em pouco tempo, aumentando rapidamente, é agora que se deve aproveitar o bônus demográfico oferecido pela composição da população em idade ativa. Isto poderia, certamente, aumentar a capacidade de poupança e de investimento, o que seria importante para atender às demandas futuras da população idosa.

\section{A população idosa}

O tamanho e a participação da população de 65 anos e mais, como já dito, aumentarão continuamente durante a TEE, aproximando-se de $20 \%$ da população total; uma proporção mais alta daquela encontrada, hoje, em qualquer país europeu. ${ }^{10}$ Assim, em 2050, o Brasil defrontar-se-á com a difícil situação de atender uma sociedade mais envelhecida do que a da Europa atual, onde uma transição etária muito mais lenta, concomitante com o desenvolvimento social e econômico, não foi capaz, ainda, de convertê-la numa sociedade justa para todas as idades. A questão é saber se, num curto período de tempo, o Brasil - que tem uma distribuição, tanto de renda como de serviços sociais, notavelmente injusta - será capaz de enfrentar, com êxito, este desafio. Behrman et al. (2001) mostram que, particularmente na América Latina, quando a participação da população de grupos etários mais velhos (e mais desiguais) aumenta, as desigualdades tendem a crescer. $\mathrm{Na}$ formulação de políticas para enfrentar estes desafios, a TEE deveria não só ser levada em conta, mas, acima de tudo, ser aproveitada, em suas diferentes fases, como instrumento de superação dos problemas por ela mesma gerados.

$O$ desafio colocado pela TEE para a população idosa relaciona-se à necessidade de geração de recursos e de construção de infra-estrutura que permitam um envelhecimento ativo. Esta condição é imprescindível, ademais, por razões econômicas. As simulações anteriores demonstraram que, sem mudanças estruturais, haverá um sério risco de profundo desequilíbrio fiscal, sendo que o envelhecimento ativo é uma forma de amenizar este risco, pois, como argumenta a OMS/WHO (2002), idosos ativos e saudáveis consomem consideravelmente menos recursos. $O$ envelhecimento ativo é sinônimo de uma vida saudável, participativa e com seguridade social.

- Previdência social

A Previdência Social no Brasil, como na maior parte dos países da América Latina, é baseada no sistema de repartição simples, que funcionou de forma satisfatória em populações relativamente jovens, quase-estáveis. Atualmente, enfrentam crises estruturais, não-demográficas, crônicas. Aumentos na longevidade, ocorrendo simultaneamente com a TEE, agravarão, ainda mais, o desequilíbrio fiscal do país se, entre outras medidas, a idade de aposentadoria não mudar. Como mostrado anteriormente, sem reformas no sistema atual, transferências em direção às populações mais velhas consumirão metade dos gastos governamentais relacionados à idade, em 2025, ou cerca de dois terços em 2050. Isto, claro, partindo do pressuposto de que haverá recursos disponíveis. O complexo sistema de previdência social brasileiro é um dos poucos em que uma idade mínima para aposentadoria não é universalmente imposta. De acordo com as mudanças mais recentes, a maior parte dos trabalhadores no setor privado pode se aposentar depois de 30 anos de contribuição (mulheres) ou 35 anos (homens), independentemente da idade. Uma alternativa estrutural para melhorar o cenário futuro é o aumento na idade média à aposentadoria. ${ }^{11}$ Reformas

\footnotetext{
${ }^{10}$ A maior proporção de pessoas com 65 anos e mais na Europa, no qüinqüênio 2000/2005, está na Itália (18,8\%) (Nações Unidas, 2003).

${ }^{11} \mathrm{~A}$ OECD tem publicado vários estudos recomendando esta alternativa em países desenvolvidos (veja, por exemplo, OECD, 1998). Veja, também, Heller (2003).
} 
recentes, introduzidas no Sistema Brasileiro de Seguridade Social, mudaram a legislação relativa aos funcionários públicos, requerendo, dos novos contribuintes, uma idade mínima para aposentadoria de 55 anos (mulheres) ou de 60 anos (homens). Os débitos crescentes do sistema, provavelmente, forçarão a introdução de limitações de idade, similares, para os trabalhadores do setor privado. Novas estratégias, como manter os benefícios de pensão constantes em termos reais, em vez de atrelá-los às variações nos salários da população ativa (salário mínimo), terão que ser adotadas.

Incentivos para permanecer por mais tempo na força de trabalho podem amenizar o peso fiscal e resultar, ao mesmo tempo, em pensões permanentemente mais altas após a aposentadoria. Esta alternativa tem sido incluída nas propostas recentes de mudanças na legislação do Sistema de Seguridade Social Brasileiro. Outrossim, o incentivo para se aposentar mais tarde poderia aumentar o desemprego, em um contexto de altos níveis de desemprego estrutural, como é o caso brasileiro. Assim, mais uma vez, o crescimento econômico e o conseqüente aumento do nível de emprego tornam-se imprescindíveis para poder aproveitar as oportunidades e superar os desafios gerados pela transição da fecundidade.

Por outro lado, retornar ao mercado de trabalho após ter se aposentado já é um fato no Brasil. Em torno de um terço dos aposentados são economicamente ativos no país (LIBERATO, 2003). Isto acontece, em parte, devido à idade jovem de aposentadoria: 56,5 anos em média (FÍGOLI, 2000); mas, principalmente, porque, apesar do "generoso programa de seguridade social", os benefícios são distribuídos de maneira desigual e uma proporção importante dos aposentados $(60 \%)$ recebe pagamento mensal de, somente, um salário mínimo. Em importantes aglomerados urbanos da América Latina, São Paulo entre eles, aproximadamente $80 \%$ dos aposentados ou pensionistas que retornam à força de trabalho apontam necessidades econômicas como a principal razão para tal (PAN AMERICAN HEALTH ORGANIZATION, 2000).

\section{- Assistência à saúde para a população idosa}

Sabe-se que a demanda por cuidados de saúde relacionada à população idosa é diferente daquela apresentada pelo resto da sociedade, devido à incapacidade e ao processo degenerativo, que requerem grandes gastos em equipamentos, medicamentos e recursos humanos capacitados. A magnitude do aumento dos custos da assistência à saúde, em função do envelhecimento da população, advém, em parte, da proporção de idosos com problemas crônicos (ou seja, com necessidades permanentes de atenção à saúde). Estima-se que entre $75 \%$ e $80 \%$ da população de 60 anos e mais na América Latina tem pelo menos uma doença crônica (PAN AMERICAN HEALTH ORGANIZATION/2000). Uma estimativa conservadora para o Brasil, aplicando esta proporção para o início do século, resultaria em algo mais de 11 milhões de pessoas com 60 anos ou mais nesta condição, contingente que poderá aumentar para 27 milhões, em 2025, e para aproximadamente 50 milhões, em 2050. Um exercício de extrapolação similar, considerando a incapacidade funcional, resultaria num número próximo dos três milhões de pessoas idosas por volta de 2005 nesta condição (6,7 milhões em 2025 e 12 milhões em 2050).

Dadas as limitações do sistema de saúde pública brasileiro, o rápido processo de envelhecimento aponta para a necessidade de se redefinirem as políticas deste setor, com o intuito de prevenir, ou pelo menos atenuar, o desamparo das gerações mais velhas.

Em relação à saúde pública, em geral, sabe-se que os serviços de saúde são direcionados principalmente para a saúde materno-infantil e reprodutiva e para lidar com as doenças infecciosas. Com o progresso da transição epidemiológica no Brasil, este enfoque está mudando e a saúde pública deve privilegiar políticas de prevenção, centralizando-se, por exemplo, nas doenças crônicas que, sem atenção médica, muito freqüentemente geram incapacidade. Entre as outras prioridades está, sem dúvida, a formação de recursos humanos para serviços geriátricos e gerontológicos, desde o nível primário de atenção 
à saúde, até tratamentos de alta complexidade. Os investimentos neste campo, pela sua própria natureza, levam considerável tempo para frutificar. A definição e implementação de uma nova política nesta área deveriam merecer a maior das atenções, para evitar, no médio e longo prazos, problemas gravíssimos, dado o rápido processo de envelhecimento da população.

- Participação - redes sociais e suporte intergeracional

O aumento da longevidade e o rápido crescimento do peso relativo da população idosa, aliados às deficiências no sistema público de saúde, magnificam a importância das redes sociais de apoio aos idosos. Há fortes evidências de que uma rede social sólida contribui, em muito, para um maior bem-estar das pessoas idosas. ${ }^{12} \mathrm{Na}$ cidade de São Paulo, mais da metade das pessoas idosas, com pelo menos uma incapacidade, recebe suporte de parentes próximos (parceiro, filho ou genro/nora), os quais fazem parte das redes "informais" que oferecem suporte às pessoas da terceira idade (PAN AMERICAN HEALTH ORGANIZATION, 2001). A mesma pesquisa identifica São Paulo entre as cidades com níveis relativamente elevados de interação entre o idoso e a comunidade (PELÁEZ e WONG, 2004). O suporte intergeracional funciona, também, na direção oposta: a família, muito freqüentemente, usufrui a aposentadoria ou pagamento de pensão dos idosos, particularmente entre os pobres e na área rural. Segundo Camarano (2002), estes pagamentos explicam, em boa parte, a associação entre contribuição de idosos para a renda domiciliar e arranjos familiares. Tratase de um mecanismo que, em princípio, promove a integração da família e que pode, ou não, favorecer o bem-estar do idoso.

Em resumo, incentivar o desenvolvimento das redes sociais é uma maneira de facilitar os cuidados com a saúde e de criar oportunidades para melhoria das condições de vida dos idosos. É necessário, conseqüentemente, levar em consideração este recurso, de baixo custo financeiro, e estimular sua formação. As redes devem incluir, acima de tudo, a família e parentes mais próximos, que constituem os potenciais "cuidadores" do idoso, na presença inexorável da degeneração biológica, em paralelo ao aparato governamental, certamente insuficiente.

\section{Considerações finais}

Independentemente dos mecanismos que determinaram a TEE, a janela de oportunidades, por ela propiciada, ofereceu condições favoráveis para a sociedade reformular várias de suas políticas públicas referentes à educação e saúde infantil. Seria ingenuidade acreditar que, por si só, a diminuição no número de nascimentos, em termos relativos ou absolutos, e a redução na taxa de crescimento da população total, como conseqüência do declínio de fecundidade, resultarão, automaticamente, na solução dos problemas sociais e econômicos (CARVALHO e WONG, 1998). Para isto, é necessária uma nova postura da sociedade, que aproveite as várias oportunidades geradas pela transição da fecundidade.

As condições favoráveis, surgidas da dinâmica demográfica, devem ser seriamente levadas em conta, na definição das políticas públicas. Uma redefinição de prioridades, tendo em vista o novo padrão demográfico, na alocação de recursos, garantindo ganhos sociais e econômicos mais elevados, a médio e longo prazos, é uma necessidade urgente. O bônus está presente somente no lado demográfico da equação população-desenvolvimento. No caso brasileiro, muitas das oportunidades já foram perdidas, porque políticas apropriadas não foram implementadas a tempo. Um exemplo refere-se à baixa qualidade do ensino dado aos jovens brasileiros, pertencentes a coortes relativamente menores, que hoje estão às

\footnotetext{
${ }^{12}$ Cohen, S. (2001) apresenta um inventário de estudos internacionais relacionados com redes.
} 
vésperas de ingressar no mercado de trabalho. ${ }^{13}$

Outra oportunidade gerada pela TEE irá se revelar durante as quatro primeiras décadas deste século: enquanto a parte mais madura da população em idade ativa (25 ou mais anos de idade) crescerá a taxas positivas, aquela mais jovem (15 a 24 anos) diminuirá em termos absolutos. Várias vantagens relacionadas a esta situação foram apontadas. Este dividendo, entretanto, só será plenamente aproveitado, se altos níveis de emprego, com aumento de produtividade, forem alcançados.

Uma condição necessária, mas não suficiente, para a conquista do equilíbrio social, econômico e intergeracional é a capacitação da força de trabalho. Por esta razão, a qualificação intelectual, técnica e profissional deve se constituir em prioridade das políticas relacionadas à população jovem. A sociedade deve despertar para o fato de que os jovens de hoje serão aqueles que terão que sustentar, no futuro, o contingente de idosos, que crescerá ra-

\section{Referências bibliográficas}

AQUINO, R. C.; PHILIPPI, S. T. Consumo infantil de alimentos industrializados e renda familiar na cidade de São Paulo. Rev. Saúde Pública, v.36, n.6, p.655-660, dez. 2002.

BARRETO, S. A. J.; CYRILLO, D. C. Análise da composição dos gastos com alimentação no Município de São Paulo (Brasil) na década de 1990. Rev. Saúde Pública, v.35, n.1, p.52-59, fev. 2001.

BEHRMAN J. R.; DURYEA, S.; SZÉKELY, M. Aging and economic opportunities: major world regions around the turn of the century. In: Proceedings of the IUSSP General Conference. Salvador, Brazil, 2001. pidamente e comporá uma proporção crescente da população total do país.

Em perspectiva, qualquer exercício que simule os gastos governamentais no futuro produzirá cenários bem conhecidos: grupos populacionais mais velhos demandarão recursos massivos, a médio e longo prazos, seja pelo lado da previdência social, seja pelo fato de que é nas idades mais avançadas que os cuidados com a saúde tornam-se mais necessários e onerosos.

A maior parte das recomendações aqui discutidas, relacionadas aos impactos da TEE, assemelha-se àquelas feitas para os países desenvolvidos em décadas passadas. Suas experiências devem ser consideradas, no entanto, levando-se em conta, acima de tudo, a grande diferença de velocidade das mudanças demográficas nos países em desenvolvimento. ${ }^{14}$ Portanto para aproveitar a janela de oportunidades e preparar a sociedade para os desafios conseqüentes, é extremamente importante que a sociedade se conscientize do pouco tempo disponível para se definir e implementar os planos e políticas adequados.

BLOOM, D. E.; WILLIAMSON, J. G. Demographic transitions and economic miracles in emerging Asia. World Bank Economic Review,v.12, n.3, p. 419-56, 1988.

BOWMAN, M.J. Education, population trends, and technological change. In: ESPENSHADE and STOLNITZ (Eds.). Technological prospects and population trends, AAAS (American Association for the Advancement of Science), Selected Symposium 103, Washington, DC, 1987.

CAMARANO, A.A. Brazilian population aging: differences in well-being by rural and urban areas. Rio de Janeiro, Ipea, 2002 (Texto para discussão, 878).

\footnotetext{
${ }^{13}$ Pesquisa mencionada por Glewwe e Kremer (2005) revela que um, em cada quatro estudantes de 15 anos do ensino médio, não consegue entender, com clareza, um texto relativamente simples de português.

${ }^{14}$ Veja, por exemplo, Ogawa et al., Nações Unidas/ESCP (1983).
} 
CAMARGO A. B.; FRIAS L.A. de M. Some aspects of the brazilian mortality: the $X X$ th century and perspectives - brazilian demography. Salvador, Brazil: IUSSP, 2001.

CARVALHO, J.A. M. de; WONG, L.R. Demographic and socioeconomic implications of rapid fertility decline in Brazil: a window of opportunity. In: MARTINE, G.; DAS GUPTA, M.; CHEN, L. (Eds.). Reproductive change in India and Brazil. Oxford University Press, 1988, p. 208-240.

COHEN S. Social relationships and health: Berkman \& Syme (1979). Advances in Mind-Body Medicine. John E. Fetzer Institute. Department of Psychology at Carnegie Mellon University. Berkman LF, 17, p.5-7, 2001.

DATASUS - Ministério da Saúde. Informações de Saúde. Disponível em: < http://tabnet. datasus.gov.br>. Acesso em 01 jul. 2004.

DEMOGRAPHIC AND HEALTH SURVEYS Macro International Inc.; BEMFAM Sociedade Civil Bem-Estar Familiar no Brasil. Brasil, pesquisa sobre saúde familiar no Nordeste. Rio de Janeiro, 1997.

DOYLE, E. I.; FELDMAN, R. H. L. Factors affecting nutrition among middle-class adolescents in urban area of Northern region of Brazil. Rev. Saúde Pública, v.31, n.4, p.342-350, ago. 1997.

FÍGOLI M. G. B. Envelhecimento populacional e comportamento das aposentadorias urbanas no Brasil. In: WONG, L. (Coord.). O envelhecimento da população brasileira e o aumento da longevidade subsídios para políticas orientadas ao bemestar do idoso. Cedeplar/UFMG/ABEP, 2000, p.127-164.

GAMA, S.G.N.; SZWARCWALD, C. L.; LEAL, M.C. et al. Gravidez na adolescência como fator de risco para baixo peso ao nascer no Município do Rio de Janeiro, 1996 a 1998.

Rev. Saúde Pública, v.35, n.1, p.74-80, fev. 2001.

GLEWWE, P.; KREMER, M. Schools, teachers, and education outcomes in developing countries. Harvard College at Harvard University. Center for International
Development - CID, September 2005 (Working Paper, 122).

IBGE - Instituto Brasileiro de Geografia e Estatística. Disponível em: <http:// www.ibge.gov.br/brasil_em_sintese/ default.htm >. Acesso em 01 jul. 2004.

Pesquisa de Orçamentos Familiares 2002-2003 - análise da disponibilidade domiciliar de alimentos e do estado nutricional no Brasil. Rio de Janeiro, 2004.

IPEA - Instituto de Pesquisas Econômicas Aplicadas. Radar Social - 2005. Rio de Janeiro: Diretoria de Estudos Sociais Disoc, 2005.

INEP - Instituto Nacional de Estudos e Pesquisas Educacionais Anísio Teixeira. Os desafios do Plano Nacional de Educação, setembro 2004.

LINDH, T.; MALMBERG, B. Age structure effects and growth in the OECD, 1950-1990. Journal of Population Economics, 12(3), p. 431-450, 1999.

LIBERATO, V. C. A oferta de trabalho masculina "pós-aposentadoria" Brasil urbano - 1981/2001. Dissertação de mestrado. Belo Horizonte: Cedeplar/UFMG, 2003.

MOREIRA, M.M. de. Envelhecimento da população brasileira. Tese de doutorado. Belo Horizonte: Cedeplar/UFMG, 1997.

MUNIZ O. J. As descontinuidades demográficas exercem efeito sobre o mercado de trabalho metropolitano dos jovens? Dissertação de mestrado. Belo Horizonte: Cedeplar/UFMG, 2003.

NAVANEETHAM, K. Age structural transition and economic growth: evidence from south and southeast Asia. In: Proceedings of the IUSSP General Conference. Salvador, Brazil, 2001.

OGAWA N.; SADAHIRO, A.; KONDO M. et al. Demographic-economic model building for Japan. In: UNITED NATIONS/ ESCAP. Modelling Economic and Demographic Development. Asian Population Studies, n. 54, p.117-223, 1983. 
PAN AMERICAN HEALTH ORGANIZATION/ MERCK INSTITUTE OF AGING. The state of aging and health in Latin America and the Caribbean. Washington DC, 2004.

PAN AMERICAN HEALTH ORGANIZATION. SABE - Survey Salud y Bienestar de la Población Adulta Mayor, 2000.

PELAEZ, M.; WONG, R.L. Vejez y recursos sociales en América Latina. Monografías Humanitas 1 Envejecimiento. Barcelona: Fundación Medicina y Humanidades Médicas, 2004, p. 73-84.

PELIANO, A.M. et al. Pesquisa Nacional de Saúde e Nutrição. Brasília: Inan/IBGE/Ipea, 1990.

PERPÉTUO, I. O. H.; WONG, L. R. Programas y políticas nacionales que afectaron el curso de la fecundidad en el Brasil. In: Seminar La Fecundidad en América Latina y El Caribe: Transición o Revolución? Santiago, Chile: Celade, June, 9-11, 2003.

POOL, I. Age-structural transitions and policy: towards frameworks. In: Seminar IUSSP/Asian Meta-Centre, Age-Structural Transitions and Policy, Phuket, Dec. 2000.

RIANI, J. L. R. Impactos da estrutura etária em indicadores de educação no Brasil, 1991. Revista Brasileira de Estudos de População, v.18, n.1/2, p.15-33, jan./dez. 2001.

SILVA LEME, M.C.; WAJNMAN, S. A alocação do tempo dos adolescentes brasileiros entre o trabalho e a escola. ENCONTRO NACIONAL DE ESTUDOS POPULACIONAIS, 12, Caxambu, 2000. Anais... Belo Horizonte: ABEP, 2000.

SILVA, L. S. M. da; GIUGLIAN, E. R. J.; AERTS, D. R. G. de C. Prevalência e determinantes de anemia em crianças de Porto Alegre, RS, Brasil. Rev. Saúde Pública, v.35, n.1, p.66-73, fev. 2001.

SAWYER, O. D.; WONG, L.R.; CARVALHO, J.A. M.; FÍGOLI, M.; ANDRADE, F.C.D.; BARBIERI, A. F.; TAVARES, C.R.G. Projeção populacional, por sexo e grupos qüinqüenais, das Unidades da Federação, Brasil, 1990-2020. Belo Horizonte: Cedeplar-UFMG (Pronex), 1999.

TURRA, C. M. Contabilidade das gerações: riqueza, sistemas de transferências e conseqüências de mudanças no padrão demográfico brasileiro. Dissertação de mestrado. Belo Horizonte: UFMG/Cedeplar, 2000.

Intergenerational accounting and economic consequences of aging in Brazil. In: Proceedings of the IUSSP General Conference. Salvador, Brazil, 2001.

UNITED NATIONS. World population prospects - the 2002 revision. New York: Department of Economic and Social Affairs - Population Division, 2003.

UNESCO. Virtual Educa 2005 - educação, capital e desenvolvimento: o papel da educação à distância. Disponível em: <http://www.unesco.org.br/noticias/opiniao/ i n d ex/virtualed u c a $2005 /$ mostra_documento>. Acesso em: out. 2005.

WONG, R. L. A projeção da fecundidade um exercício aplicado ao Brasil para o período 1991-2020. ENCONTRO NACIONAL DE ESTUDOS POPULACIONAIS, 12, Caxambu, 2000. Anais... Belo Horizonte: ABEP, 2000

OECD. The retirement decision-OECD Economic Outlook, June, 1998 OECD Publications and Information - Centre in association with The Gale Group. Disponível em: < http://www.findarticles.com/cf_dls/ m4456/n63/20792419/print.jhtml>. Acesso em 12/01/2004.

SCHWARZER, H.; QUERINO A.C. Benefícios sociais e pobreza: programas não contributivos da seguridade social brasileira. Brasília: Ipea, 2002 (Texto para discussão, 929).

WORLDHEALTHORGANIZATION. Active aging - a policy framework. Noncommunicable Disease Prevention and Health Promotion Department, Aging and the Life Course, 2002. 


\begin{abstract}
The rapid process of aging in Brazil: serious challenges for public policies

The positive effects of the recent age structure transition (AST) in Brazil can be seen in children's health services, education and other areas. The higher growth rate estimated for the economically active population in coming decades constitutes a new area of opportunities. The combination of the older segment of the labor force (ages 25 to 64), which is showing high growth, with the junior segment (ages 15 to 24), which is showing very low or even negative growth rates, indicates a trend toward reducing the demographic pressure for new jobs. The training of the future labor force has become an indispensable component for a more just intergenerational, social and economic balance. Due to the age structure transition, new challenges are emerging related to the expansion of the older population. If the present per capita transfer of funds from the government is maintained constant, the difference between revenue and expenses will increase, causing an unsustainable fiscal deficit. The expected crisis brought about by the aging of the population and the current irrational social security system must be urgently discussed in Brazilian society. The best must be made of the opportunities generated by age structure transition in order to prepare to face the new resulting challenges.
\end{abstract}

Key words: Aging. Age structure transition. Public policies. Demographic window of opportunities.

Recebido para publicação em 03/11/2005.

Aceito para publicação em 17/03/2006. 